\title{
Variable-Stiffness Composite Panels: Defect tolerance under in-plane tensile loading
}

\author{
O. Falcóa ${ }^{\mathrm{a}}$,J. A. Mayugo ${ }^{\mathrm{a}}$, C. S. Lopes ${ }^{\mathrm{b}}$, N. Gascons ${ }^{\mathrm{a}}$, J. Costa $^{\mathrm{a}}$ \\ ${ }^{a}$ AMADE, Polytechnic School, Universitat de Girona, Campus Montilivi s/n, 17071 Girona, Spain \\ ${ }^{b}$ IMDEA Materials - Madrid Institute for Advanced Studies of Materials, c/Eric Kandel, 2, Parque \\ Científico y Tecnológico-Tecnogetafe, 28906 Getafe, Madrid, Spain.
}

\begin{abstract}
Automated Fiber Placement is being extensively used in the production of major composite components for the aircraft industry. This technology enables the production of tow-steered panels, which have been proven to greatly improve the structural efficiency of composites by means of in-plane stiffness variation and load redistribution. However, traditional straightfiber architectures are still preferred. One of the reasons behind this is related to the uncertainties, as a result of process-induced defects, in the mechanical performance of the laminates. This experimental work investigates the effect of the fibre angle discontinuities between different tow courses in a ply on the un-notched and open-hole tensile strength of the laminate. The influence of several manufacturing parameters are studied in detail. The results reveal that 'ply staggering' and '0\% gap coverage' are effective techniques in reducing the influence of defects in these laminates.
\end{abstract}

Keywords:

A. Carbon fibers; B. Defects; Variable-Stiffness Panels;

\section{Introduction}

Nowadays, Automated Fiber Placement (AFP) of carbon-fiber-reinforced composites is widely applied in the aerospace industry. The use of this technology permits the manufacture of larger structures, providing more strength and stiffness where needed while ensuring high quality and shorter production times [1]. The AFP process automatically places multiple individual preimpregnated tows onto a mandrel at high speed using a numerically controlled

Email address: ja.mayugo@udg.edu (J. A. Mayugo) 
placement head to dispense, clamp, cut and restart each tow during placement. AFP systems make the production of Non-Conventional Laminate concepts (NCLs) possible [2]. Among these concepts are the Variable-Stiffness Panels (VSP), where the fibers follow curved paths, and which are noted not only for their structural performance and versatility, but also for their design complexity [3-6]. The results of compression testing the VSP specimens confirm that they are particularly suitable in resisting buckling, because it is possible to transfer the higher stresses from the interior to the edge of the panels [7]. Also, the VSP are able to improve first-ply failure responses, for example in laminates with a central hole [8]. Despite these potential advantages and the developments of AFP manufacturing over the past two decades, conventional straight-fiber laminates based on $0^{\circ}, 90^{\circ}, \pm 45^{\circ}$ ply angles are still predominantly used.

Typically, an AFP machine has the capability of placing up to 32 (1/8 in.) fiber tows within a single course width. This means that within each head pass or course, up to 32 tows are placed parallel to each other. A reference path shift occurs discretely at multiples of the course width. Within a given course, the fiber orientation deviates from the reference path which is only followed by the course centreline. The maximum deviation is at the edges of the course, which results in a fiber-angle mismatch between adjacent courses. The wider the courses, the larger this discontinuity is. These geometric discontinuities can be the cause of stress concentrations which in turn, can hinder the performance expected from the idealized structure, i.e. one with a continuous variation of the fiber orientation along one of the planar coordinates.

There are two manufacturing approaches to deal with the converging tows at the VSP course edges: the tow-overlapping and the tow-dropping methods [9-11]. If the tows overlap, thicker regions are created which can act as stiffeners in the laminate. Conversely, the towdrop method avoids overlapping zones by cutting the individual tows at their intersection point, so that thickness does not build up. As a result, small defects consisting of resin rich zones without fibers, called gaps, are created at the boundaries of the tow-placement course. In both methods, these gap and overlap zones can become potential spots for the initiation of matrix cracking or even delaminations as a result of the local amplification of interlaminar stresses. Different methods have been introduced with the aim of reducing 
the influence of these defects on the structural response. Some of which are: the hybrid combination of curvilinear plies with straight-fiber plies (mainly placed at the outer layers), the staggering technique [12], and the variation of the gap coverage parameter [4]. On one hand, the staggering technique avoids the nucleation of the defects that would occur in the same places through-the-thickness of a laminate in plies of the same steering configuration. Staggering reduces the concentration of the resin area (gaps), thus increasing the load transfer effectiveness and making smooth thickness laminates possible. On the other hand, the gap coverage parameter is used to minimize the presence of gaps due to tow-dropping. This parameter determines the degree to which the discrete gaps are covered by fibers, and can vary gradually from $0 \%$ to $100 \%$-in which case gaps cease to exist, but small triangle tow-overlaps are created instead.

Several approaches and numerical analyses have been performed to optimize VSP design [13-17]. Other studies - e.g. on buckling response, thermal stresses analyses, strength and stiffness - with the aim of obtaining an adequate understanding of the behavior of these laminates have been developed and validated by experimental work [18-24]. However, the full details of the mechanisms that lead to failure and the mechanical response of a VSP are not yet fully understood, particularly the influence of embedded defects, mainly gaps, overlaps and the fiber angle discontinuities induced by AFP [25, 26]. It is worth mentioning the theoretical and numerical investigation on the influence of the tow-drop areas and staggering on the stiffness and strength of variable-stiffness laminates presented by Blom et al.[12]. Additionally, Blom et al. expanded their studies from tailored flat panels to cylindrical and conical shells $[27,28]$. In the latter cases, the effects of gaps and overlaps were analyzed in a global sub-component level.

The certification of variable-stiffness laminates requires high-level component tests in order to understand the effect of the defects on the mechanical response and failure mechanism of the laminates. Some of these defects have been the object of research [29, 30]. Recently, Nicklaus [31] explored the effect of converging gap defects in the open-hole compressive strength and mode-I fracture toughness. He points out that these ply gaps (resin pockets) produce higher fracture toughness values in the critical stress area adjacent to the hole. Similarly, Croft et al. [32], presented an experimental study quantifying the effect of the 
main manufacturing-induced defects. Their work reveals the influence of these defects in the mechanical response of composite laminates under tensile, compression and shear loading. It is worth noting that, in that study, the defects were manually inserted during specimen manufacture and were not the result of a real tow-drop or tow-overlap procedure in an AFP machine.

The present work aims to quantify the effects on laminate strength of tow-drop defects found in a real AFP manufacturing environment. Three different configurations were considered: $100 \%$ gap coverage (allowing small overlaps), $0 \%$ gap coverage and $0 \%$ gap coverage with ply staggering. The configurations analyzed have been compared with an equivalent baseline laminate without defects. Initially, the real defect geometry was analyzed using detailed micrographs. Then, these laminate configurations were tested under monotonic tensile loading for un-notched and open-hole specimens. The Digital Image Correlation (DIC) technique has been used to analyze the full strain field and to observe the influence of defects, particularly in those zones prone to damage, just before the final structural collapse. Additionally, the failure mechanisms have been analyzed with the help of high-resolution photography.

\section{Specimen design and manufacturing}

The test specimens for the experimental work reported in this paper have been designed to represent the ply discontinuities at the edges of adjacent courses in VSP configurations. Accordingly, each specimen represents a sub-domain of a whole panel, as shown in Fig. 1a. The maximum tow-angle mismatch $\left(\theta_{1}-\theta_{2}\right)$, represented in Fig. 1b for different VSP configurations with linear fiber-angle variations, is dependent on panel dimensions, course width (or number of tows per course, $n_{\mathrm{t}}$ ) and fiber angles at the center $\left(T_{0}\right)$ and at the edges of the panel $\left(T_{1}\right)$ [3]. In Fig. 1b only those configurations with $T_{0}=0^{\circ}$ are considered, as these lead to the worst-case tow-angle mismatch scenarios. Likewise, a panel side of $700 \mathrm{~mm}$ in the direction of fiber-angle variation is considered as a limit case. For a panel smaller than this, the maximum variation between $T_{0}$ and $T_{1}$ would be bounded by the minimum machine turning radius in order to keep an acceptable laminate quality. Hence, a maximum theoretical mismatch angle of $13^{\circ}$ is achieved. In reality, the angle $T_{1}=90^{\circ}$ is never achieved 
in practice due to finite tow-width and discrete tow-cutting [25]. For the tensile specimen design in this work, a discontinuity of $12^{\circ}$ was been selected as a reasonable approximation to the worst-case scenario.

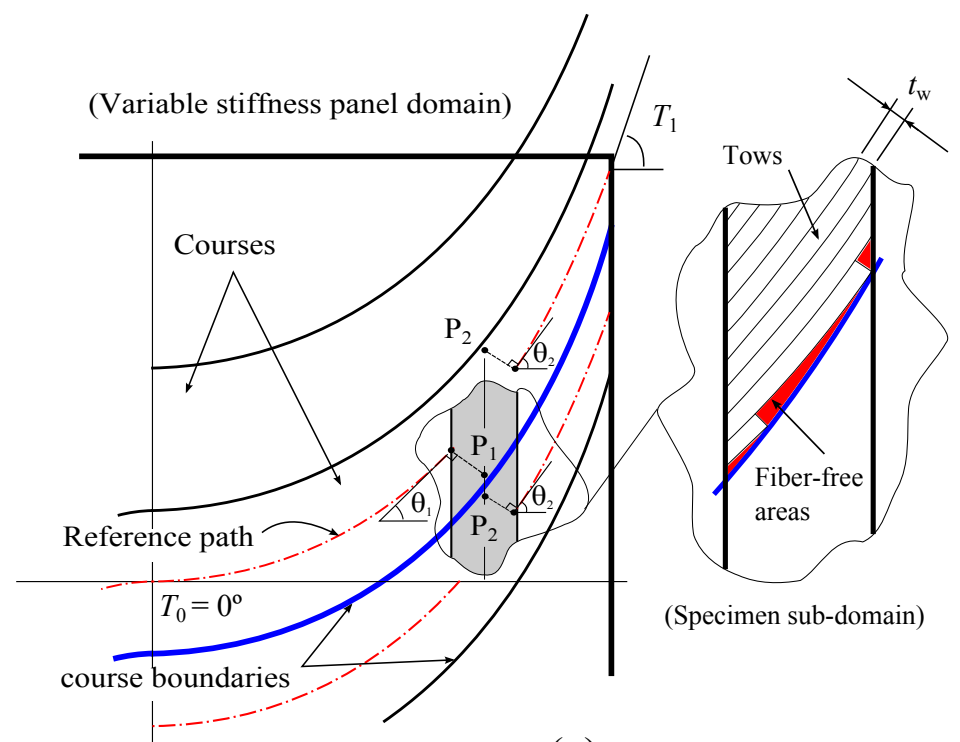

(a)

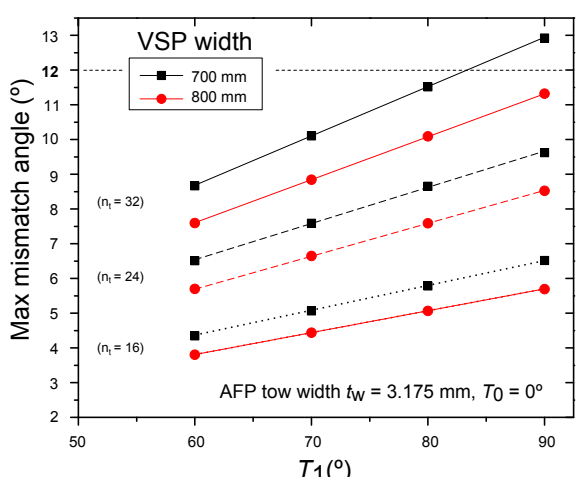

(b)

Figure 1: a) Tensile specimen sub-domain definition in a Variable Stiffness Panel. b) Maximum mismatch angle $\left(\theta_{1}-\theta_{2}\right)$ between the boundary of the courses for panels of $700 \mathrm{~mm}$ and $800 \mathrm{~mm}$ for $T_{0}=0^{\circ}$ and different $T_{1}$ values.

The specimens consist of straight-fiber layers since, considering the small dimensions of the specimens, there is negligible difference between the actual curved trajectory and a straight one. Some layers in the laminate have one portion with the fibers at $51^{\circ}$ and another at $39^{\circ}$, thus creating an angle discontinuity at the specimen mid-length. To avoid more complexity, these plies with angle discontinuity were balanced with plies at $-45^{\circ}$. Both the Un-Notched Tensile (UNT) and the Open-Hole Tensile (OHT) specimens have the same outer dimensions: length $(L)$ of $310 \mathrm{~mm}$, width $(W)$ of $32 \mathrm{~mm}$ and tab length $L_{\text {tab }}$ of 65 $\mathrm{mm}$. The specimen geometry is depicted in Fig. 2a.

The material used in this investigation is the HexPly AS4/8552 pre-impregnated CFRP in $6.35 \mathrm{~mm}\left(1 / 4\right.$ in.) wide tows $\left(t_{\mathrm{w}}\right)$. The nominal ply thickness after curing is $0.18 \mathrm{~mm}$.

The lay-up analyzed is $\left[45 / 0 /-45 / 90 /\left(-45_{2} /(51 \mid 39)_{2}\right)_{2}\right]_{s}$. The design of the external plies was constrained to the conventional straight-fiber method to avoid gaps or overlap defects in the outer layers of the laminate. All configurations present the same stacking 
sequence (24 plies) with nominal laminate thickness of $4.32 \mathrm{~mm}$. A baseline laminate with a staking sequence of $\left[45 / 0 /-45 / 90 /\left(-45_{2} / 45_{2}\right)_{2}\right]_{s}$ has also been analyzed and tested for comparative purposes. The baseline and non-conventional laminates were designed to have similar global stiffness. The elastic properties of the material system are $E_{11}=138.0 \mathrm{GPa}$, $E_{22}=8.6 \mathrm{GPa}, G_{12}=4.9 \mathrm{GPa}, \nu_{12}=0.35$.

Three configurations with tow-drop defects have been designed and tested. The configurations are described in Fig. 2b. The difference between the three is in the variation of the gap coverage parameter and the use of the staggering technique. In one configuration, tows are cut avoiding any overlapping, hence generating a triangular fiber gap ( $0 \%$ gap coverage). In another configuration, tows are allowed to overlap by just the required amount to avoid these gaps (100\% gap coverage). As a result, right-triangular gaps or overlaps appear in the laminate. The dimension of one leg is the width pf the tow and its opposite angle is the discontinuity angle (see Fig. 2b). In our case, the triangle legs are $6.35 \mathrm{~mm}$ and 29.9 $\mathrm{mm}$ respectively. In these two configurations, gaps and overlaps are co-located through the thickness of the laminate for plies with the same steered configuration. In a third configuration, the co-location of gaps is avoided by staggering the plies in relation to each other. The staggering distance is twice the width of the tow $(12.70 \mathrm{~mm})$ along the transverse direction to the $51^{\circ}$ tows (see Fig. $2 \mathrm{~b}$ ).

Four plates were manufactured with a Coriolis Fiber Placement Machine in the National Aerospace Laboratory (NLR) in the Netherlands. The material was cured in a two-step cycle $-110^{\circ} \mathrm{C}$ during $60 \mathrm{~min}$ followed by $180^{\circ} \mathrm{C}$ for $120 \mathrm{~min}$ - according to manufacturer specifications for monolithic components. All plates were C-scan inspected to ensure the laminate quality. For the un-notched specimens, tabs are mandatory to avoid excessive stresses near the clamping jaws. E-glass fabric prepreg tabs at $\pm 45^{\circ}$ were glued to the specimen with epoxy adhesive and tapered with the nominal slope of 1 in 4 . After curing the laminates, the specimens were cut using a $2.5 \mathrm{~mm}$ thick diamond blade. The central hole of the open-hole tensile specimens was drilled with a $6.3 \mathrm{~mm}$ diameter multi-directional drill. The specimens were checked to ensure they were within tolerance and free from delaminations after the cutting process. 

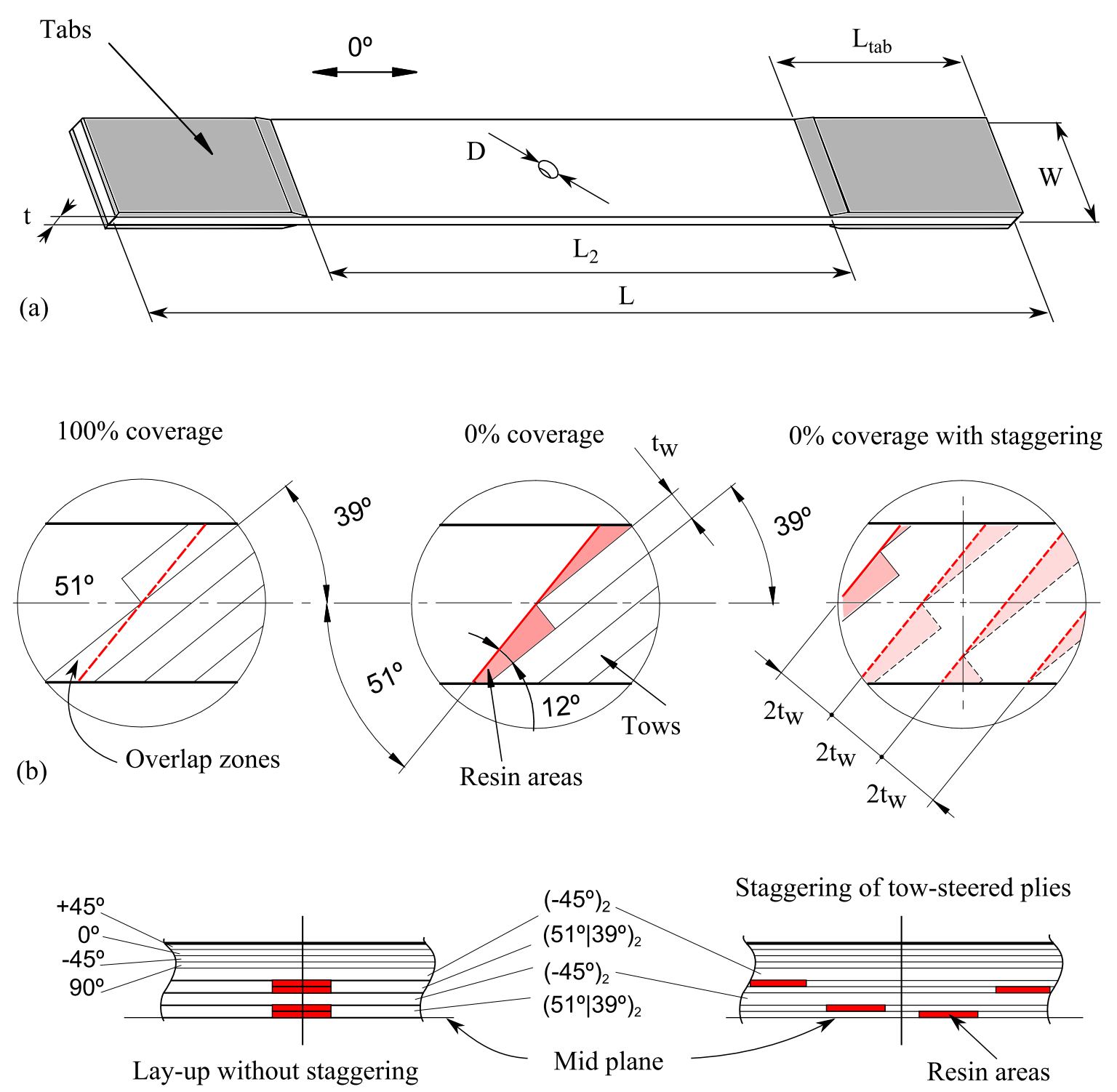

(c)

Figure 2: a) Specimen geometry. (b) Tow-drop gap defects (100\% gap coverage, $0 \%$ gap coverage and $0 \%$ gap coverage with staggering). The discontinuity interface in the ply $\langle 51 \mid 39\rangle$ is represented using a red line and resin rich areas are shaded in red. (c) Tow-drop specimen lay-up with and without staggering.

\section{Real tow-drop defect geometry}

This section scrutinizes the two-drop defects induced in the three configurations through an in-depth analyses of thickness measurements and micrographic images.

The micrographic observation reveals the real size and nature of the gap and overlap 
zones. This is essential for a better understanding of the mechanical response of the nonconventional laminates with these types of manufacturing defects.

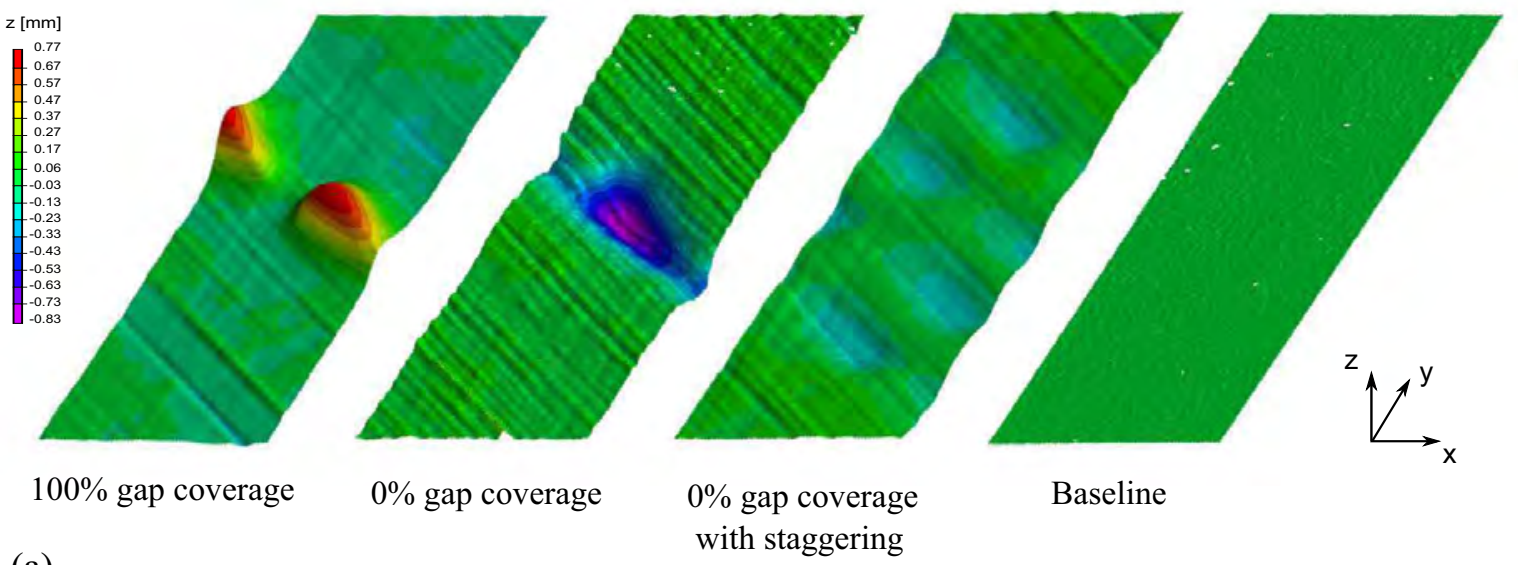

(a)

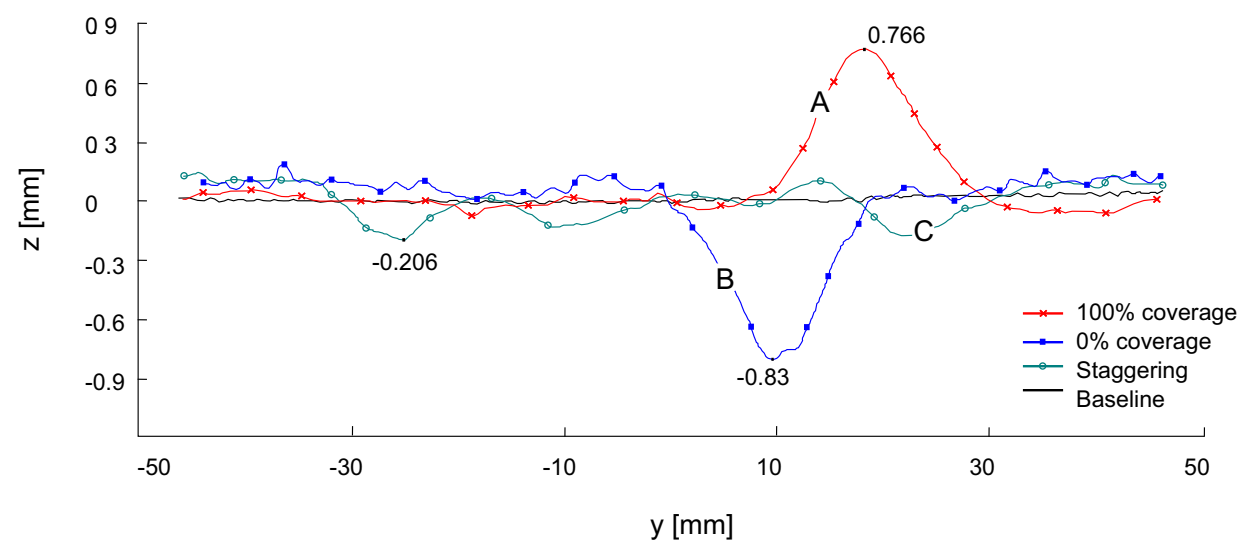

Figure 3: Profile variations on top surface of the different specimens configurations.

The real top-surface profile and dimension measurement for each configuration is precisely obtained with the VIC-3D ${ }^{\mathrm{TM}}$ system. A comparison of the surface profile in the top outer layer for each configuration is shown in Fig. 3. The thickness variations along the $\mathrm{y}$-direction of the middle line for the different configurations are compared. For the configurations without ply staggering, the tow-drop defects coincide at the same in-plane location for layers of the same configuration, which produces co-location of overlaps and gaps. For the configuration with $100 \%$ gap coverage, the laminate thickness increases by $15 \%$ due to the overlapping. Whereas, for the configuration with $0 \%$ gap coverage, the maximum thickness reduction is $20 \%$. This thickness reduction is caused by the pressing of gaps in adjacent 
layers as a result of the high pressure in the autoclave during the curing process. However, if the staggering technique is applied, the local thickness variation reduced considerable ensuing in a mere $5 \%$. The reason being that staggering reduces the superposition of defects through the laminate thickness.

The micrographic analyses were performed with a Leica DMR-XA compound light trinocular microscope (Bright Field and Fluorescent Imaging) with $50 \times$ to $1600 \times$ magnification and a resolution of 0.2 microns, together with a ProgRes C14 digital camera.

For the configuration with $100 \%$ gap coverage, an external and cut view of the specimens analyzed are shown in Fig. 4. The increase in thickness due to the ply overlapping is remarkable. The curvature of the outer layer is smooth (see Fig. 4a) as a result of the stiffness of the continuous layers during the curing process. The manufactured specimens contain significant areas of overlap, together with small triangular rich resin zones near the tow-drop sections (see Fig. 4b).

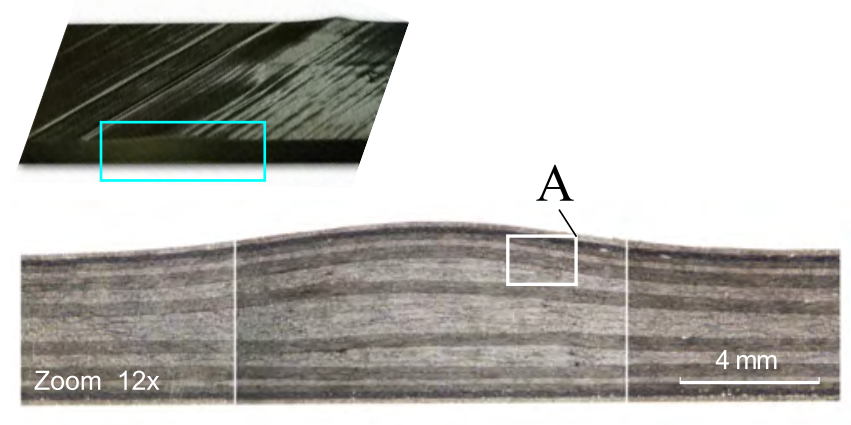

(a)

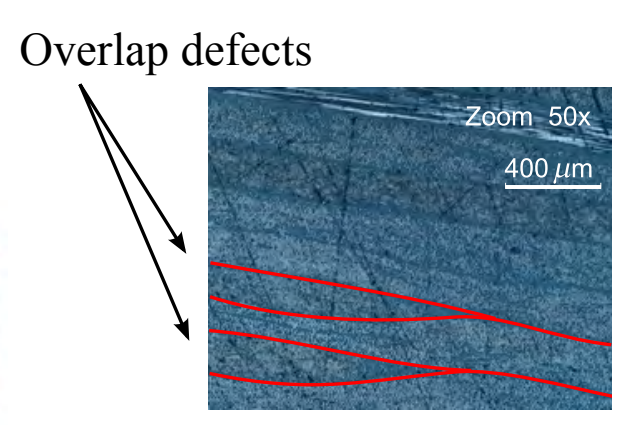

(b)

Figure 4: a) Real tow-drop defect for configuration with $100 \%$ gap coverage (magnification $12 \times$ ). b) Detailed micrography (magnification $50 \times$ ).

In order to observe the extension of the rich-resin zones in the configuration with $0 \%$ gap coverage, three different sections have been analyzed along the specimen (see Fig. 5a). While it is true that, in the section QQ', small dispersed gaps appear (see Fig. 5c, detail Q), in the sections OO' and PP', all the gaps are clustered and concentrated. Here, the size of the gap defects is notable (see Fig. 5c, detail $\mathrm{O}$ and $\mathrm{P}$ ), and the waving of the adjacent plies to fill the gap area is evident. The curvature of the plies is similar to the $100 \%$ gap coverage 
case. Higher angle differences between adjacent layers reduce the waving of the tows.

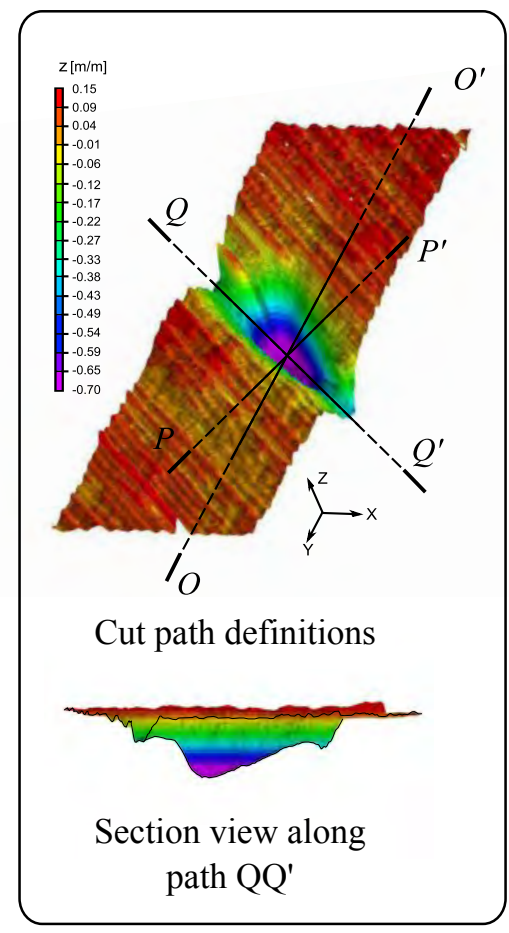

(a)

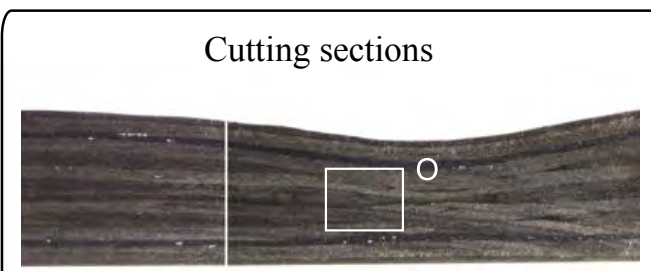

Along path $\mathrm{OO}^{\prime}$

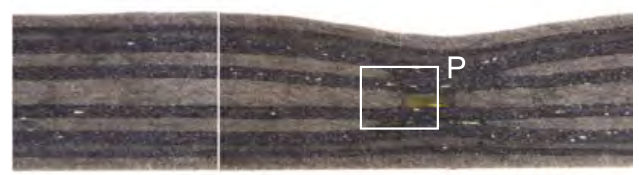

Along path $\mathrm{PP}^{\prime}$

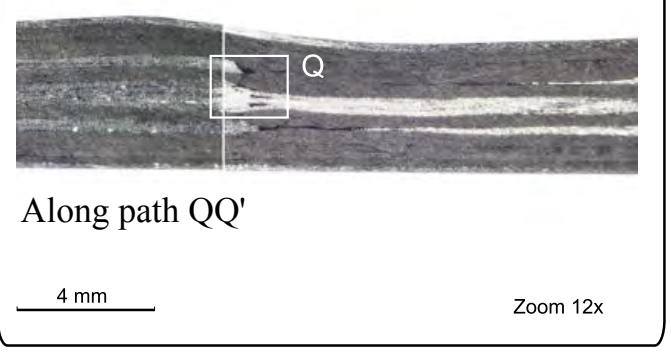

(b)
Fiber-free areas
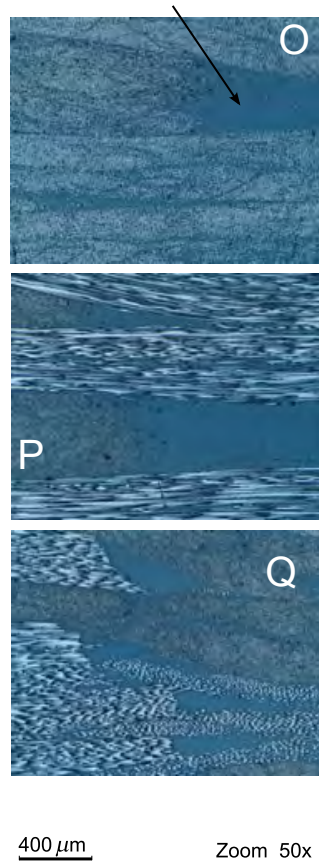

(c)

Figure 5: (a) Cut section definitions. (b) Different view for the configuration with tow-drop 0\% coverage (magnification $12 \times$ ). (c) Detailed gap micrography (magnification 50×).

If the staggering technique is applied to the $0 \%$ gap coverage case, the laminate thickness becomes more homogeneous because of the non-coincidence of gaps. A laminate surface similar to the baseline configuration is obtained, as confirmed by microscopic observation (see Fig. 6). Although clustering of defects is avoided, small resin zones still remain as the result of single gaps, as seen in the micrographic detail C in Fig. 6.

The assumption of gap areas totally filled by resin is used mainly for modeling the towdrop gaps for numerical simulation purposes in order to simplify the analysis. However, this assumption is uncertain according to the observed micrographs. In these simplifications, the effect of the high autoclave pressure on the individual plies in the laminate is neglected. For a better understanding of the failure and damage mechanisms, the real defect geometry needs to be taken into account. This work confirms the results observed by Croft et al. [32] with respect to the real defect geometry and its influence on the strength in the non-conventional 


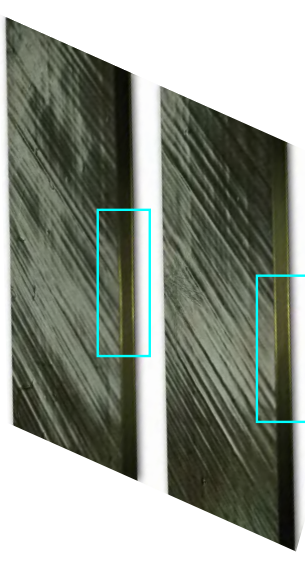

$0 \%$ gap coverage with staggering

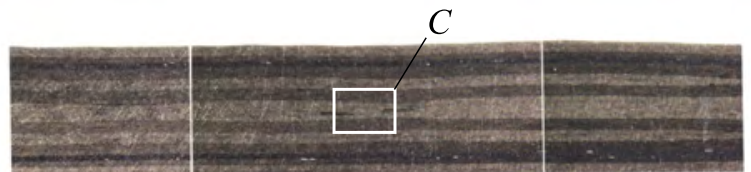

Baseline

Fiber-free areas

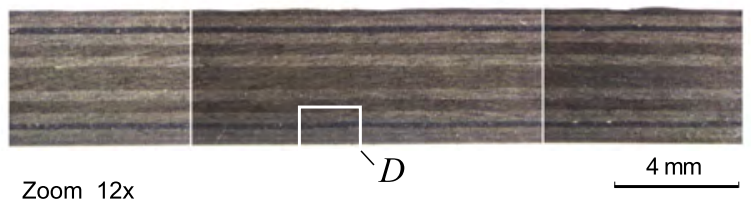

(a)
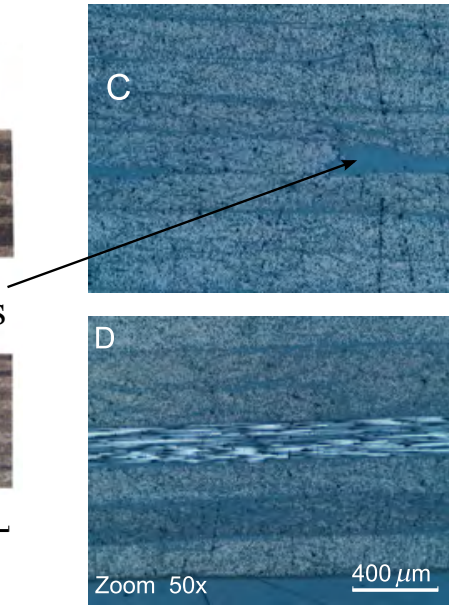

(b)

Figure 6: (a) Specimens. (b) Real tow-drop defect for the configuration with $0 \%$ coverage with staggering and the Baseline laminate (magnification $12 \times$ ). (c) Detailed defect micrography (magnification $50 \times$ ).

laminates.

\section{Experimental set-up}

Un-noched and open-hole specimens were tested using a hydraulic MTS 810 system with a $250 \mathrm{kN}$ load cell. The ASTM standard D 5766 [33] was followed to determine the open-hole tensile strength in multidirectional CFRP specimens. The data acquisition frequency used was $20 \mathrm{~Hz}$.

The VIC-3D ${ }^{\mathrm{TM}}$ Measurement System (Correlated Solutions, USA) was used in this test to measure the full-field displacements and strains on the outer $45^{\circ}$ ply with Digital Image Correlation (DIC). The DIC system set-up with a pair of stereo-mounted digital cameras is shown in Fig. 7. For real-time analog data acquisitions, the system is connected to the load output of the test frame controller, and records load and displacement data synchronously with the images.

The working distance of the DIC installation was set to $700 \mathrm{~mm}$ for the plain tensile test, whereas for the open-hole tensile it was set to $400 \mathrm{~mm}$, for an object facet size of $90 \times 32$ $\mathrm{mm}^{2}$ and $45 \times 32 \mathrm{~mm}^{2}$, respectively. The area of interest was spray painted guaranteeing the quality of the speckle pattern. The selected subset size was $29\left(29 \times 29\right.$ pixel $\left.^{2}\right)$ with a 


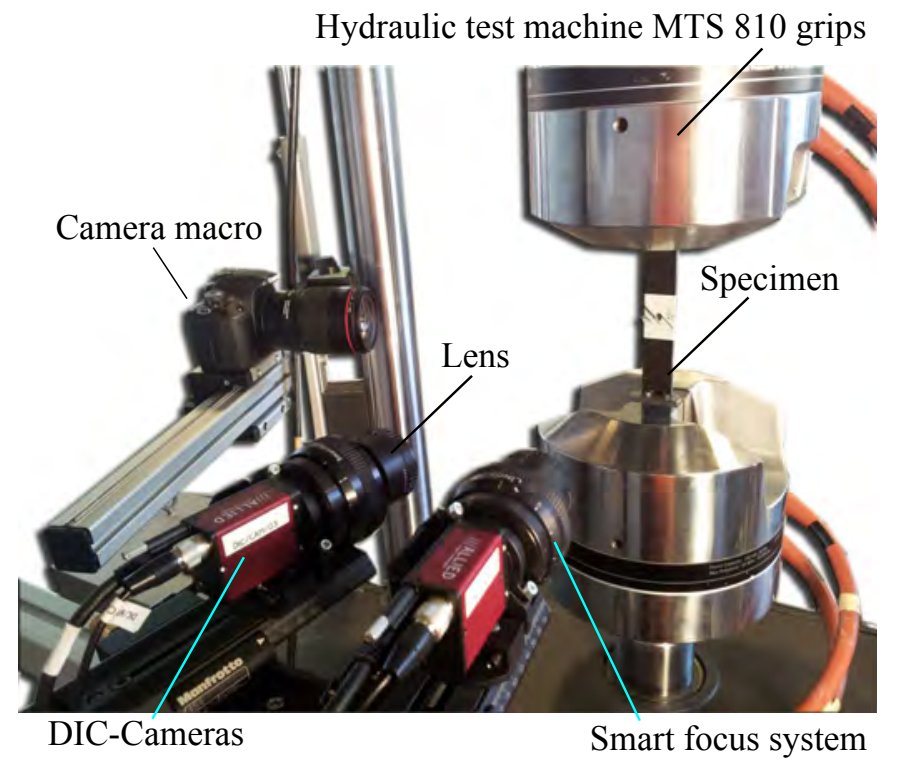

Figure 7: Open-hole tensile (OHT) specimen tensile test set-up with DIC technology included.

7 pixel step size. On the one hand, the subset size has to be large enough to ensure that there is a sufficiently distinctive pattern contained in the area used for correlation, whereas on the other hand, the step size controls the spacing of the points that are analyzed during correlation. The shutter interval time was set to $500 \mathrm{~ms}$ to be compatible with an applied displacement rate of $0.5 \mathrm{~mm} \cdot \mathrm{min}^{-1}$. In both cases, a Rodagon WA 60 lens was used with an extension tube $[1 \times]$ joined to a Smart focus system. An additional camera with an EF$100 \mathrm{~mm}$ macro lens ('camera macro' in Fig. 7) was used to observe the crack propagation on one of the free edge of specimens. All tests were monitored using the VIC-3D ${ }^{\mathrm{TM}}$ DIC system on one side. For the plain tests, strain gauges were bonded to the other side. Two strain gauges in the axial and transverse directions were placed in the middle of the specimens, with a gauge factor $k$ of $2.04 \pm 1 \%$ at $24^{\circ} \mathrm{C}$, and resistance of $350 \Omega \pm 0.30 \%$.

\section{Test results and discussion}

A total of 24 specimens were tested under tensile load up to final failure, with an average of three specimens for each configuration. The DIC was used to observe the influence of the VSP defects on the strain field until the final structural collapse. The failure is taken as being the first significant load drop in the load-displacement response. The failure mechanisms 
and the strength values were analyzed for each configuration. Previous to the failure test, a correlation between the stress-strain responses for one of the specimens was carried out. The results obtained through the DIC system, the axial strain gauge and an extensometer demonstrated very good agreement between the different techniques.

\subsection{Un-Notched Tensile (UNT) test}

The first analyses were carried out by DIC at the moment just before the final failure of the specimens, in order to observe the influence of tow-drop defects on the strain field and on the out-of-plane displacement. Three specimens with tow-drop defects were selected, one for each configuration, and their behavior was compared. The longitudinal strain $\left(\varepsilon_{\mathrm{yy}}\right)$, transverse strain $\left(\varepsilon_{\mathrm{xx}}\right)$, shear strain $\left(\varepsilon_{\mathrm{xy}}\right)$ of the outer layer at $45^{\circ}$ and displacement along the out-of-plane direction $(w)$ throughout the survey area in question are shown in Fig. 8. In all cases analyzed, the load direction and the fiber direction at $0^{\circ}$ corresponds to the vertical axis (y-direction). The fibers oriented at $51^{\circ}$ are located below the defect zone. The strain variation due to the fiber angle discontinuity of $\left(51^{\circ} \mid 39^{\circ}\right)$ can easily be seen in the DIC representations. The strains concentrate in the vicinity of the defect areas which are critical zones for damage. On the one hand, in the case of $100 \%$ gap coverage, the longitudinal strains in the tow-drop area are lower than average strains resulting in overlapping and stiffer zones. On the other hand, in the configurations with $0 \%$ gap coverage, the defects result in material zones with lower stiffness and higher strain.

The analysis of the displacement $(w)$ reveals delaminations near the edges of the specimens. In the non-staggered configurations, these delaminations are concentrated in the clustered regions of ply discontinuities. However, in the staggered specimens, the delaminations are less evident and distributed along the edge in different zones (see Fig. 9a).

The results of remote failure stress obtained for the different configurations in plain tensile test are summarized in Table 1. For plain specimens, compared with the baseline lay-up, the configurations with tow-drop defects exhibit lower tensile strength. The specimens with $100 \%$ gap coverage show a strength reduction of $10.7 \%$, while the laminates with $0 \%$ gap coverage present a more significant strength reduction of about $20.1 \%$. For the configuration 

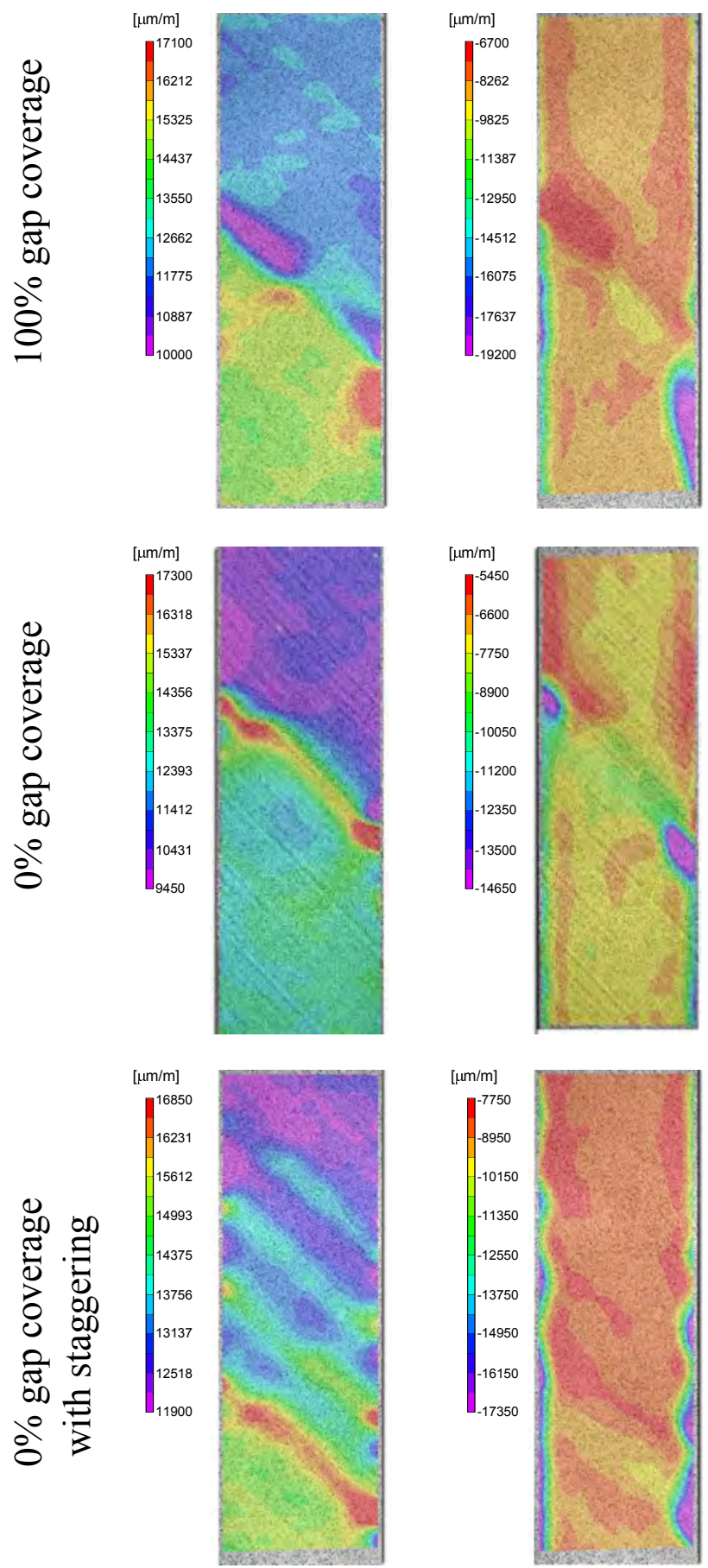

$\varepsilon_{\text {yy }}$

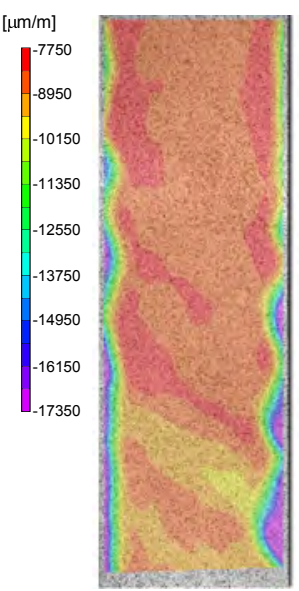

$\varepsilon_{\mathrm{xx}}$
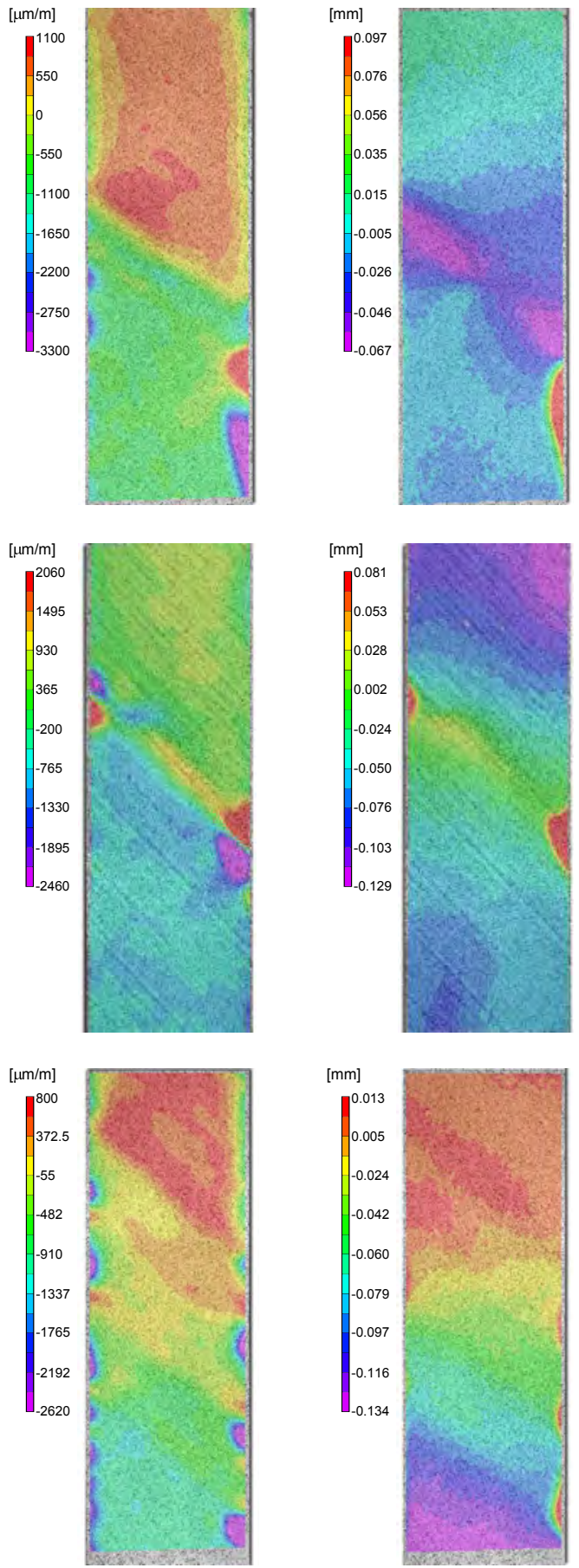

$\varepsilon_{\mathrm{xy}}$

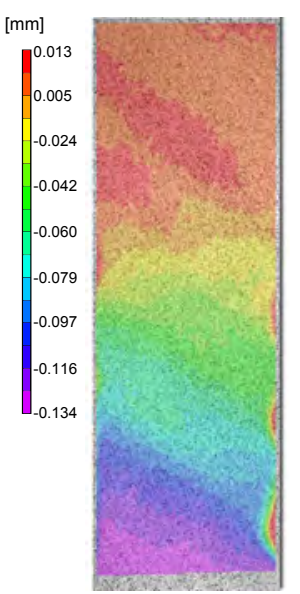

$w$

Figure 8: Strain field $(\varepsilon)$ and out-of-plane displacement $(w)$ comparison for un-notched tensile specimens on the outer layer at $45^{\circ}$ just before final failure. 
with staggering, the reduction is only $8.6 \%$. The standard deviation of the values is higher in tow-drop specimens due to the different distribution of the defects. The results show an increase of the ultimate strength for the configurations with $100 \%$ gap coverage with respect to $0 \%$ gap coverage. This can be explained by the reinforcing effect of the overlaps. The results also confirm the expected improvement obtained by means of the staggering technique applied to laminates manufactured by the tow-drop method.

Table 1: Remote failure stress for un-notched tensile (UNT) and open-hole tensile (OHT) specimens (values in $\mathrm{MPa})$. Calculated using the maximum measured stress $\left(P_{\max }\right)$ and the values of the specimen thickness $(t)$ and width $(w)$ as: $X^{\mathrm{T}}=P_{\max } /(t w)$.

\begin{tabular}{llll}
\hline Configurations & Mean (MPa) & STDV (MPa) & Normalized strength \\
\hline Un-notched tensile (UNT) & & & \\
\hline UNT Baseline & 389.2 & 0.6 & 1 \\
UNT 100\% gap coverage & 347.3 & 12.3 & 0.89 \\
UNT 0\% gap coverage & 303.1 & 21.7 & 0.78 \\
UNT Staggering (0\% coverage) & 355.8 & 9.1 & 0.91 \\
\hline Open-hole tensile (OHT) & & & \\
\hline OHT Baseline & 225.6 & 4.2 & 1 \\
OHT 100\% gap coverage & 235.9 & 6.8 & 1.04 \\
OHT 0\% gap coverage & 214.7 & 1.4 & 0.95 \\
OHT Staggering (0\% coverage) & 231.4 & 6.0 & 1.02 \\
\hline
\end{tabular}

For comparison purposes, the load-displacement curves for one specimen of each configuration are plotted in Fig. 9. The extensive non-linearity of the load-displacement curves prior to failure confirms a progressive loss of stiffness; probably as a result of both the appearance of matrix cracking in the off-axis layers, and the onset of delaminations across the tow-drop defect zones. Specimen collapse is caused by extensive fiber breakage.

In both of the non-staggered configurations, the edge photographs taken during the test reveal large free-edge delaminations in the zones with defects (Fig. 9a). For example, point O in Fig. 9a identifies the observable delamination onset on the free-edge for the configuration with $100 \%$ gap coverage, which advances up to point $\mathrm{P}$ where the specimen finally fails. This cracked zone coincides with the defect area. In such areas, the fiber angle discontinuities and the thickness variations increase the interlaminar stresses, which cause delaminations 
in the free edges. Such stresses contribute to the weakening of the specimens. Hence, the failure of the plain tensile specimens begins at the edge and propagates along the defect. The staggered laminate configuration presents a structural behavior analogous to the baseline. Both lay-ups present similar observed free-edge delaminations. The crack delaminations are small and uniformly distributed across the edge of the laminate in comparison with the non-staggered configurations. In Fig. 9a, this failure mode is shown in the image taken just before final failure (point Q).

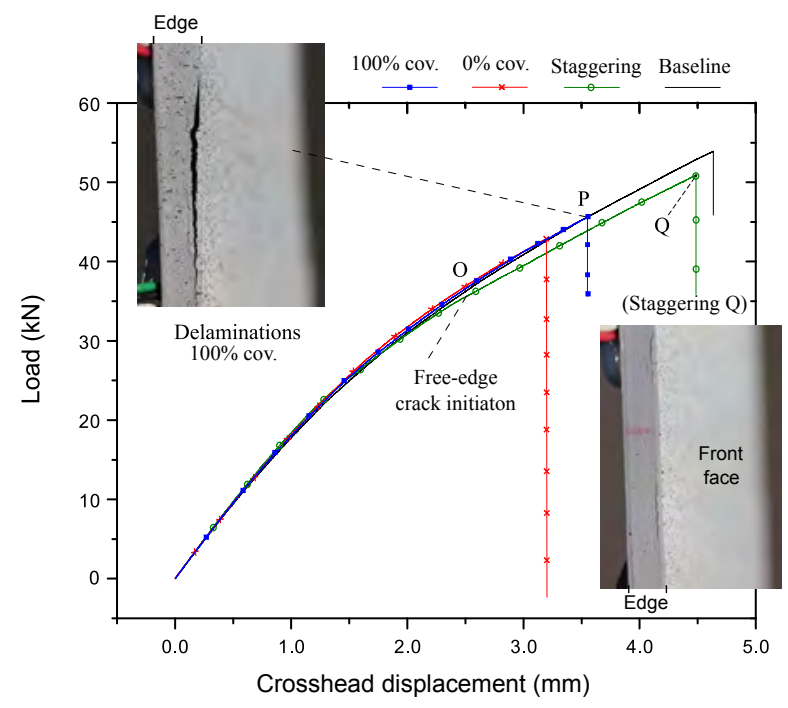

(a)

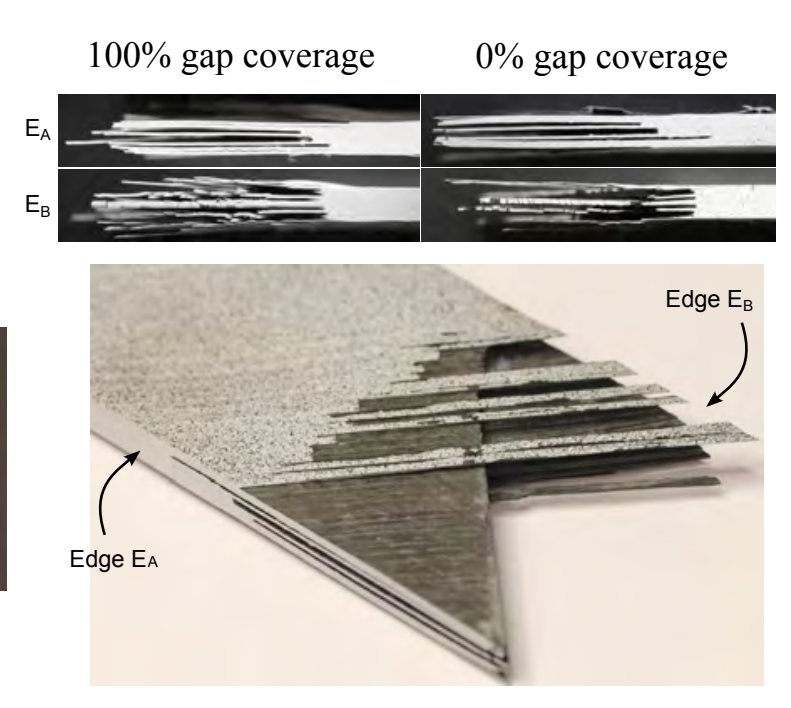

(b)

Figure 9: a) Comparison of load-crosshead displacement for different un-notched laminate configurations. (b) Delamination on tested specimen.

Post-failure examination of the specimens shows two main types of failure mechanism: fiber pull-out and delamination. The pull-out failure mechanism is caused by fiber failure mainly at the $0^{\circ}$ plies. The delamination analysis reveals that the interlaminar damage always occurs with the same pattern at the sublaminate level. This behavior is common to all the specimens tested. Therefore, this failure mechanism is likely to be more dependant on the lay-up rather than any other factor. To illustrate this, photographs of failed specimens are shown in Fig. 9b. An examination of the fractured edges of specimens (Edge $\mathrm{E}_{\mathrm{A}}$ and Edge $\mathrm{E}_{\mathrm{B}}$ ) reveals large delaminations as a result of the mismatch angles between the plies. Two delaminations appear between the outer layers and the $0^{\circ}$ laminae, whereas the other 
delaminations occur in the interfaces between the $\left(-45^{\circ}\right)_{2}$ layers and the $\left(51^{\circ} \mid 39^{\circ}\right)_{2}$ plies.

\subsection{Open-Hole Tensile (OHT) test}

In contrast to the un-notched specimens where the maximum strain appears in the towdrop-induced-defect zones, for the open-hole specimens higher strains are produced in the stress concentration spots around the hole. Although all of the OHT specimens tested present a similar fracture behavior, there are small differences between them.

In order to illustrate the longitudinal strain distribution $\left(\varepsilon_{\mathrm{yy}}\right)$, one DIC representation for each configuration has been selected and shown in Fig. 10a. The images depict the critical strain zone just before the crack initiation at the $45^{\circ}$ ply; akin to where the onset of damage and the first evident delaminations are observed. When the $100 \%$ gap coverage is compared to that of the $0 \%$ gap coverage, the first reveals lower strains in the defect direction because of stiff zones caused by the ply overlapping, while in gap zones the strains were higher. For the staggered and baseline configurations, the strain fields are nearly identical. The variations of longitudinal strain $\left(\varepsilon_{\mathrm{yy}}\right)$ along path AA' (see Fig. 10a, baseline) in y-direction for the OHT configurations are plotted in Fig. 10b. As observed, maximum deformation is governed by the increasing stress values in the adjacent zones to the hole where the damage appears, and the manufacturing-induced defects have little relevance in the final failure process.

The longitudinal strain field $\varepsilon_{\mathrm{yy}}$ for the outer layers at $45^{\circ}$ of one test specimen, just before the final catastrophic failure, for each of the configurations tested are shown in Fig. 11. Here, the $45^{\circ}$ matrix crack is clearly visible from the hole in the outer ply surface. This external damage is propagated asymmetrically across the width of the specimen to the specimen edges.

The damage mechanisms for the OHT specimen observed in this experiment were similar to those observed by other authors for OHT specimens [34, 35]. Initially, isolated matrix cracking, splitting and delaminations at the hole edge appear (see Fig. 12b). Then, damage propagates across the width of the specimen, leading to final collapse. Fiber breakage in the $0^{\circ}$ plies can only be observed after the final catastrophic failure. The failure mechanisms are represented in schematic form in Fig. 11b. Delaminations are controlled by the interlaminar shear stresses, increased by the free edge effect of the hole and the influence of the manu- 


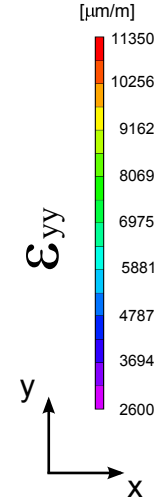

(a)

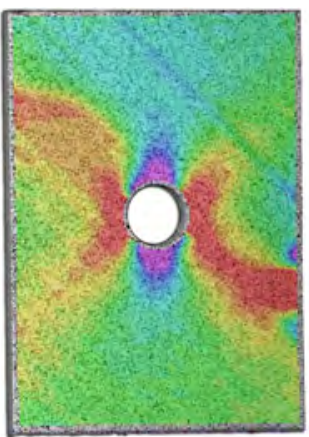

$0 \%$ gap coverage

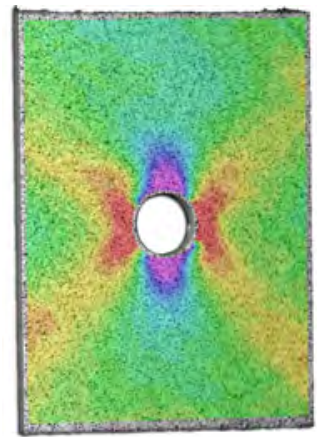

$0 \%$ gap coverage with staggering

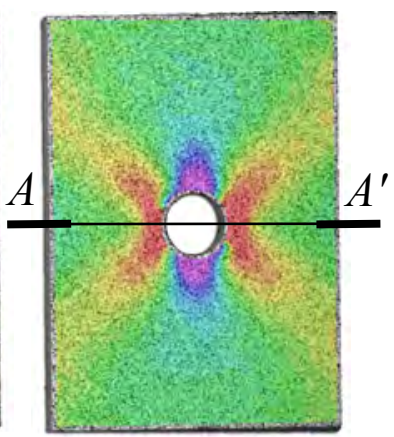

Baseline
$100 \%$ gap coverage

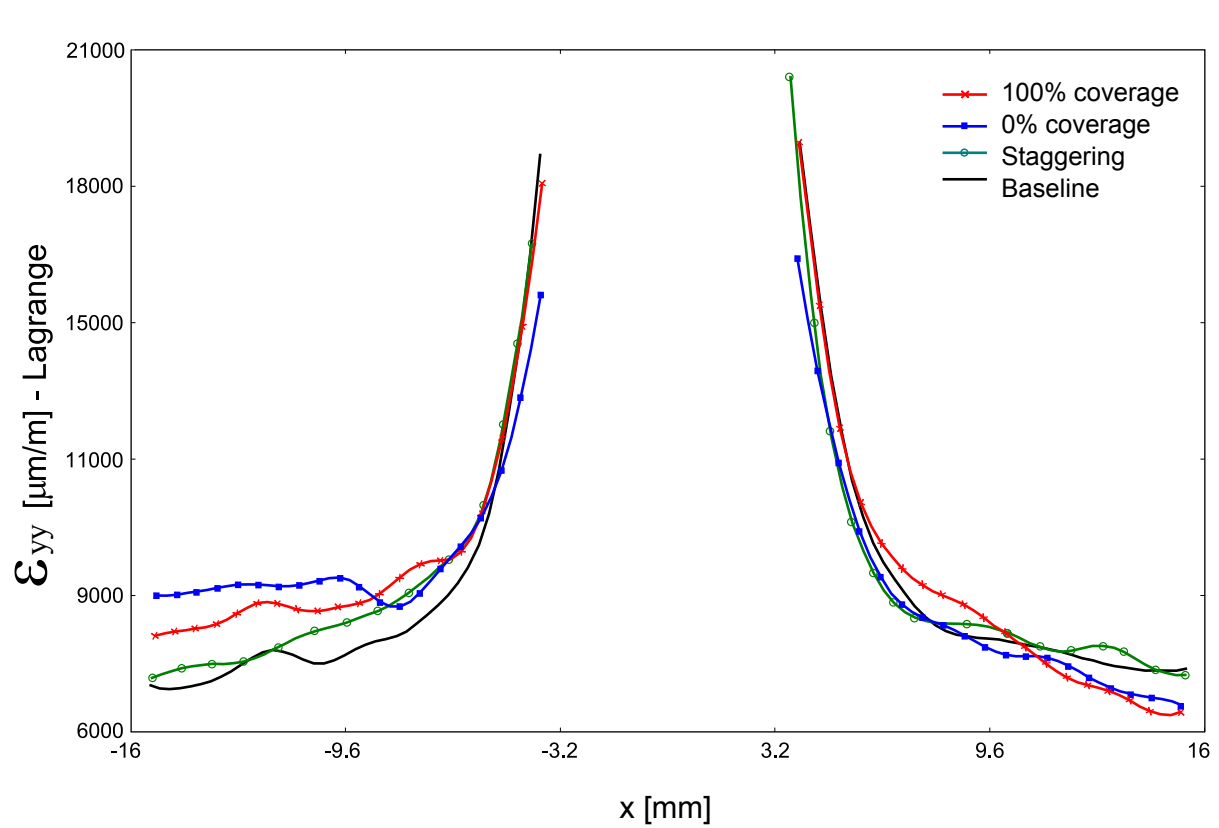

Figure 10: a) Longitudinal strain field for the outer layer of different OHT configurations just before visible crack initiation. b) Plot of the longitudinal strain $\varepsilon_{y y}$ along path AA'.

facturing induced defects. However, in contrast to the plain specimen, the influence of the open hole is more relevant than the defect itself.

The OHT test load-displacement curves for representative specimens are plotted in Fig. 12a. The results show the similarity between the staggered laminate specimens and the conventional specimens. The load-displacement curves present less non-linearity than those of the the un-notched specimens. In these specimens, the structural collapse was also controlled by a pull-out failure mechanism accompanied by delaminations. The post-fracture 


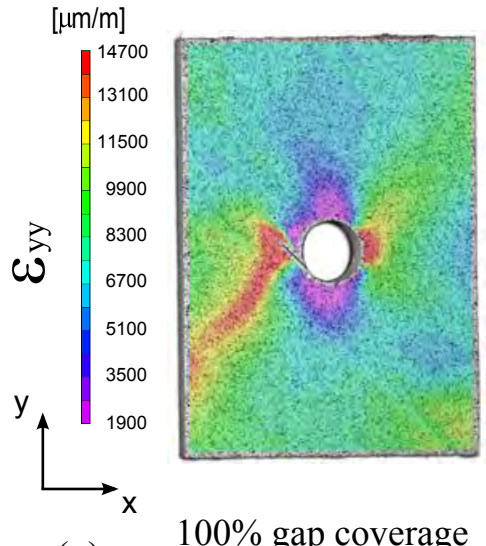

(a)

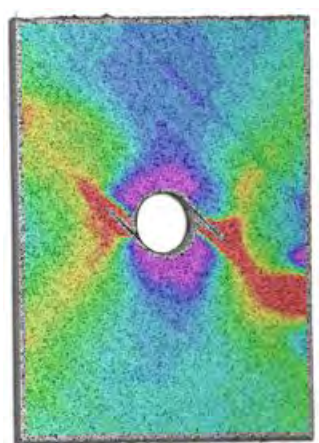

$0 \%$ gap coverage

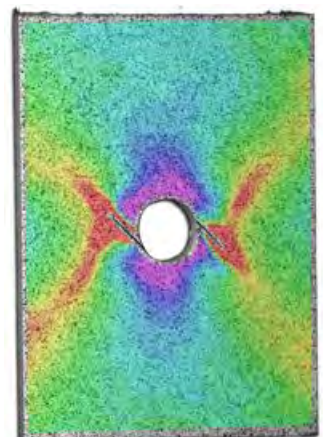

$0 \%$ gap coverage with staggering

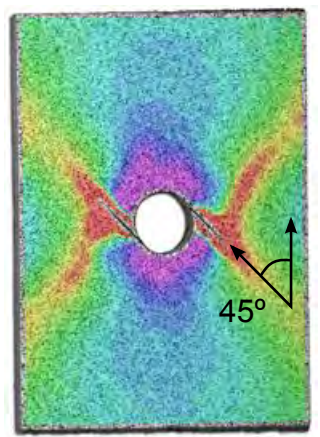

Baseline
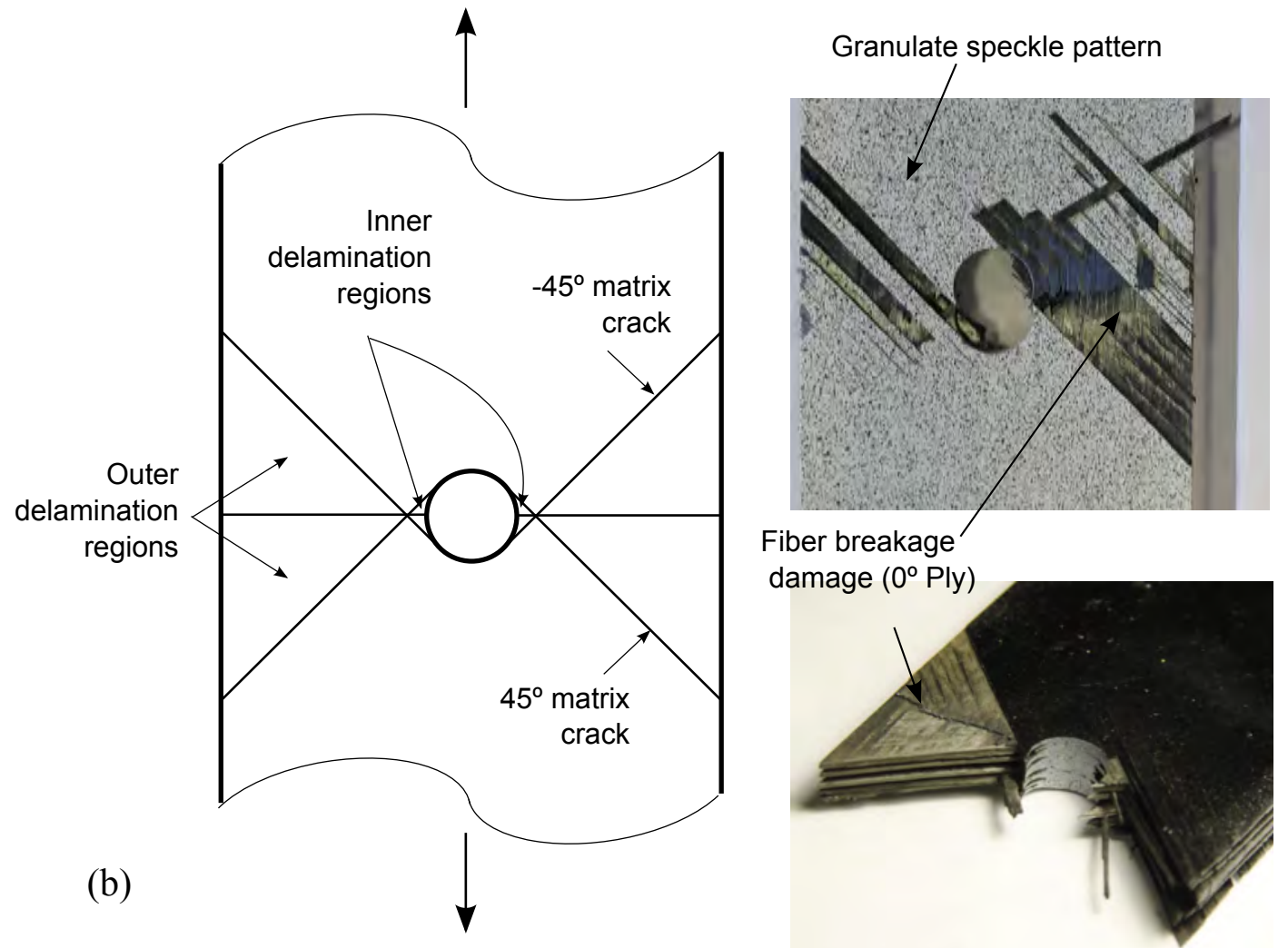

Figure 11: a) Longitudinal strain field for the outer layer of different OHT configurations just before final failure. b) Damage zones associated with the specimens.

analysis and the load-displacement behavior have a good agreement with the observed failure mechanism, as reported by Green et al. in [34].

In the outer ply the onset of damage at the hole free edge is propagated parallel to 
the fiber orientation of $45^{\circ}$. Similar sub-critical damage mechanisms were observed for all specimens, as shown in Fig. 12b. The zoom on the open-hole region reveals how the damage is initiated in the form of isolated matrix cracks and delamination at the hole edge. This damage is mainly at the interface of the plies with overlap or gaps and conventional plies without fiber angle discontinuities.

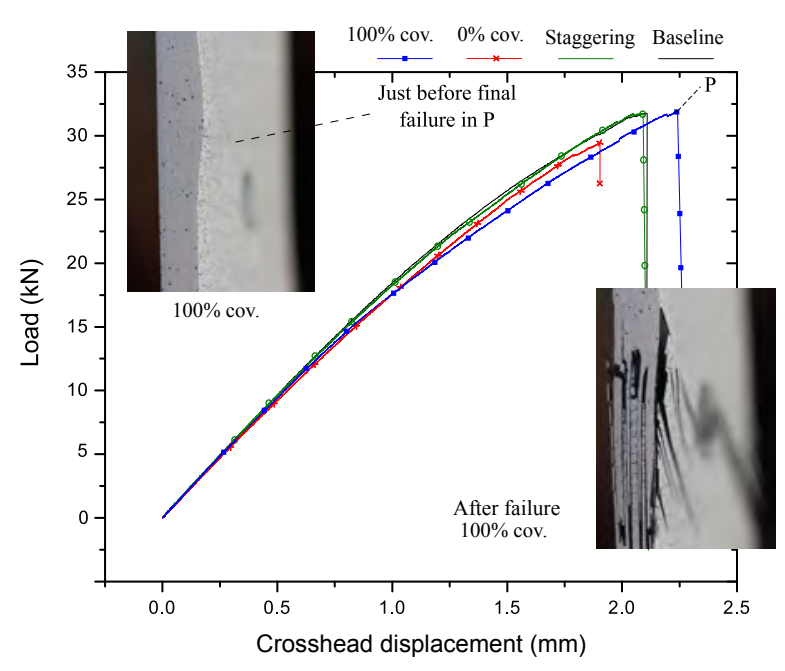

(a)

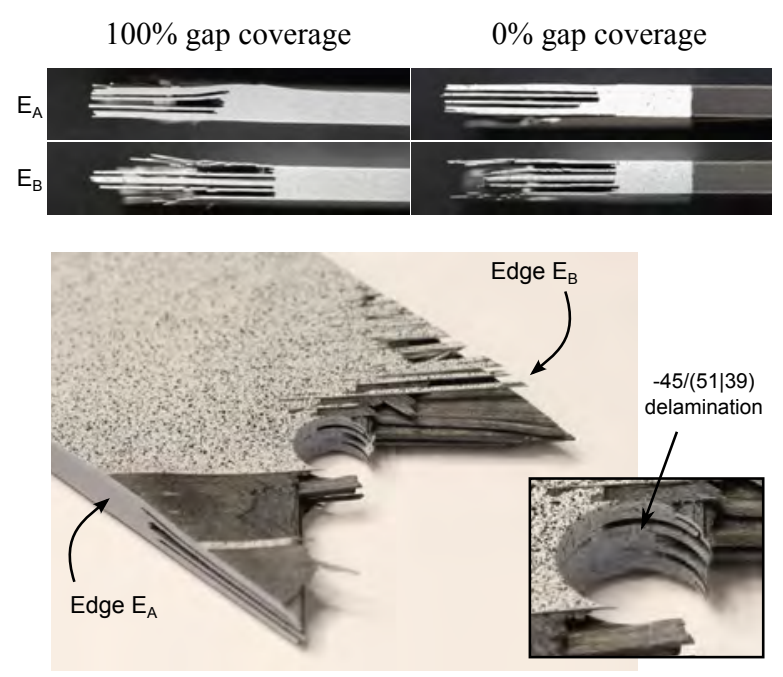

(b)

Figure 12: a) Comparison of load-crosshead displacement for different open-hole laminate configurations. (b) Delamination and damage on tested specimen.

The open-hole results present small differences of far-field stress, as specimen failure is strongly driven by the presence of the hole. This means that the stress concentration generated by the hole is little amplified by the manufacturing defects. The results of remote-failure stress obtained for the different configurations in the open-hole tensile test are summarized in Table 1.

\section{Conclusions}

In the present experimental work, the effect of the fiber angle discontinuities between different tow courses in a ply on the un-notched and open-hole laminates tensile strength was investigated. The influence of the coverage percentage and the staggering technique were studied in detail. 
Test specimens were designed and manufactured to represent a sub-domain of a VSP containing a worst-case tow-angle discontinuity, and different practical manufacturing strategies to tackle such discontinuity: i) tow-dropping with $0 \%$ gap coverage (gaps); ii) tow-dropping with $100 \%$ gap coverage (overlaps); and iii) tow-dropping with $0 \%$ gap coverage and ply staggering.

After a geometrical observation of overlapping and gap defects produced by the towdrop manufacturing method, test specimens were loaded until failure. In comparison with the baseline specimens representing straight-fiber panels without defects, the configuration with $0 \%$ gap coverage and no staggering presents the most critical strength reduction; as a results of the clustering of gaps. When the ply staggering technique is applied, these effects are highly mitigated. Therefore, 'ply staggering' and '0\% gap coverage' is an effective combination to lessen the influence of defects in VSP.

The experimental results show that the stress concentration, induced by the presence of the hole in OHT specimens, has a higher influence on failure than that induced by the presence of manufacturing defects in un-notched specimens. Additionally, the analysis of failure mechanisms in un-notched specimens reveals that large delaminations initiate in the vicinity of the tow-drop defects, which are then followed by extensive matrix cracking and finally fiber failure. This is probably caused by the amplification of the interlaminar stresses around the defects.

\section{Acknowledgements}

The authors acknowledge the financial support of the Ministerio de Economía y Competitividad of Spain under project MAT2009-07918. The first author would also like to thank Generalitat de Catalunya for the FI grant AGAUR, IUE/2365/2009.

\section{References}

[1] Lukaszewicz D, Ward C, Potter K. The engineering aspects of automated prepreg layup: history, present and future. Composites Part B: Engineering 2012;43:997-1009.

[2] Lopes CS. Damage and failure of non-conventional composite laminates. Ph.D. thesis; Delft University of Technology; 2009. 
[3] Gürdal Z, Tatting BF, Wu KC. Variable stiffness panels: Effects of stiffness variation on the in-plane and buckling responses. Composites Part A: Applied Science and Manufacturing 2008;39:911-22.

[4] Gürdal Z, Tatting BF, Wu KC. Tow-placement technology and fabrication issues for laminated composite structures. In: Proceedings of the AIAA/ASME/ASCE/AHS/ASC Structures, 46th Structural Dynamics \& Materials Conference. 2005, .

[5] Blom AW, Mostafa, Abdalla M, Gürdal Z. Optimization of course locations in fiberplaced panels for general fiber angle distributions. Composites Science and Technology 2010;70:564-70.

[6] Khani A, IJsselmuiden ST, Abdalla MM, Gürdal Z. Design of variable stiffness panels for maximum strength using lamination parameters. Composites Part B: Engineering 2011;42:546-52.

[7] Lopes CS, Gürdal Z, Camanho P. Variable-stiffness composite panels: Buckling and first-ply failure improvements over straight-fibre laminates. Computers and Structures 2008;86:897-907.

[8] Lopes CS, Gürdal Z, Camanho PP. Tailoring for strength of composite steered-fibre panels with cutouts. Composites Part A: Applied Science and Manufacturing 2010;41:176067.

[9] Gürdal Z, Olmedo R. In-plane response of laminates with spatially varying fiber orientations - variable stiffness concept. AIAA J 1993;31(4):751-8.

[10] Tatting BF, Gurdal Z. Design and manufacture of elastically tailored tow placed plates. Tech. Rep. NASA/CR-2002-211919; NASA; 2002.

[11] Wu KC, Gürdal Z, Starnes JH. Structural response of compression-loaded, tow-placed, variable stiffness panels. In: Proceedings of the 43rd AIAA/ASME/ASCE/AHS/ASC Structures, Structural Dynamics and Materials Conference. Denver, CO; 2002,AIAA 2002-1512. 
[12] Blom AW, Lopes CS, Kromwijk PJ, Gürdal Z, Camanho PP. A theoretical model to study the influence of tow-drop areas on the stiffness and strength of variable-stiffness laminates. Composite Materials 2009;43:403-25.

[13] Nagendra S, Kodiyalam S, Davis JE, Parthasarathy VN. Optimization of tow fiber paths for composite design. In: Proceedings of the AIAA/ASME/ASCE/AHS/ASC 36rd Structures, Structural Dynamics and Materials Conference, New Orleans, LA. 1995, p. 1031-41.

[14] Jegley DC, Tatting BF, Gürdal Z. Optimization of elastically tailored tow placed plates with holes. In: Proceedings of the AIAA/ASME/ASCE/AHS/ASC 44th Structures, Structural Dynamics and Materials Conference. Norfolk, VA; 2003,AIAA 2003-1420.

[15] Setoodeh S, Abdalla MM, Gürdal Z. Design of variable-stiffness laminates using lamination parameters. Composites Part B: Engineering 2006;37:301-9.

[16] Blom AW, Stickler PB, Gürdal Z. Optimization of a composite cylinder under bending by tailoring stiffness properties in circumferential direction. Composites Part B: Engineering 2010;41:157-65.

[17] Nik MA, Fayazbakhsh K, Pasini D, Lessard L. Surrogate-based multi-objective optimization of a composite laminate with curvilinear fibers. Composite Structures 2012;94:2306-13.

[18] Nagendra S, Gürdal Z, T. HR. Buckling and failure characteristics of compression-loaded stiffened composite panels with a hole. Composite Structures 1994;28:1-17.

[19] Gürdal Z, Tatting BF. Design and manufacture of tow-placed variable stiffness composite laminates with manufacturing considerations. In: Proceedings of the 13th U.S. National Congress of Applied Mechanics. 1998,.

[20] Wu KC, Gürdal Z. Thermal testing of tow-placed variable stiffness panels. In: Proceedings of the 42nd AIAA/ASME/AHS/ASC Structures, Structural Dynamics and Materials. 2001,. 
[21] Jegley DC, Tatting BF, Gürdal Z. Tow-steered panels with holes subjected to compression or shear loading. In: Proceedings of the 46th AIAA/ASME/AHS/ASC Structures, Structural Dynamics and Materials. 2005,.

[22] Wu KC, Gürdal Z. Variable stiffness panel structural analysis with material nonlinearity and correlation with tests. In: Proceedings of the 47th AIAA/ASME/ASCE/AHS/ASC Structures, Structural Dynamics and Materials. 2006,.

[23] Lopes CS, Camanho P, Gürdal Z, Tatting BF. Progressive failure analysis of tow-placed, variable-stiffness composite panels. Solids and Structures 2007;44:8493-516.

[24] Setoodeh S, Abdalla MM, IJsselmuiden ST, Gürdal Z. Design of variable-tiffness composite panels for maximum buckling load. Composite Structures 2009;87:109-17.

[25] Falcó O, Mayugo JA, Lopes CS, Gascons N, Turon A, Costa J. Variable-stiffness composite panels: As-manufactured modeling and its influence on the failure behavior. Composites Part B: Engineering 2014;56:660-9.

[26] Nik MA, Fayazbakhsh K, Pasini D, Lessard L. Optimization of variable stiffness composites with embedded defects induced by automated fiber placement. Composite Structures 2014;107:160-6.

[27] Blom AW, Stickler BF, Gürdal Z. Design and manufacture of a variable-stiffness cylindrical shell. In: Proceedings of the SAMPE Europe 30th International Conference. 2009 .

[28] Blom AW, Tatting BF, Hol JM, Gürdal Z. Fiber path definitions for elastically tailored conical shells. Composites Part B: Engineering 2009;40:77-84.

[29] Sawicki Adan J, Minguet PJ. The effect of intraply overlaps and gaps upon the compression strength of composite laminates. In: Thirty-nineth AIAA structural, dynamics, material conferences, Structural Dynamics and Materials Conference. Long Beach, CA; 1998, p. $744-54$. 
[30] Turoski LE. Effects of manufacturing defects on the strength of toughened carbon/epoxy prepeg composites. Master's thesis; Montana State University, Mechanical Engineering, Bozeman; 2000.

[31] Nicklaus CK. Open hole compressive behavior of laminates with converging gap defects. Master's thesis; Department of Mechanical Engineering, The University of Utah; 2011.

[32] Croft K, Lessard L, Pasini D, Hojjati M, Chen J, Yousefpour A. Experimental study of the effect of automated fiber placement induced defects on performance of composite laminates. Composites: Part A: Applied Science and Manufacturing 2011;42:484-91.

[33] ASTM. Open hole tensile strength of polymer composite laminates. Tech. Rep.; American Society for Testing and Materials (ASTM); West Conshohocken, PA, USA; 2003. ASTM D 5766/D 5766M-02.

[34] Green BG, Wisnom MR, Hallett SR. An experimental investigation into the tensile strength scaling of notched composites. Composites Part A: Applied Science and Manufacturing 2007;38:867-78.

[35] Hallett SR, Green BG, Jiang WG, Wisnom MR. An experimental and numerical investigation into the damage mechanisms in notched composites. Composites Part A: Applied Science and Manufacturing 2009;40:613-24. 